\title{
Stress Degradation Studies on Lisinopril Dihydrate Using Modified Reverse Phase High Performance Liquid Chromatography
}

\author{
Elsadig H. K. Adam \\ Department of Pharmaceutical Chemistry, College of Pharmacy, Salman bin Abdulaziz University, Al-Kharj, KSA \\ Email: elsadigk@yahoo.com, e.adam@sau.edu.sa
}

Received 27 February 2014; revised 31 March 2014; accepted 9 April 2014

Copyright (c) 2014 by author and Scientific Research Publishing Inc.

This work is licensed under the Creative Commons Attribution International License (CC BY). http://creativecommons.org/licenses/by/4.0/ (c) (i) Open Access

\begin{abstract}
A simple, precise, accurate and sensitive reverse phase high performance liquid chromatographic method for simultaneous estimation of lisinopril dihydrate and its degradation products occuring under different ICH prescribed stress conditions has been modified. Drug was resolved on a C18 column, utilizing modified mobile phase of tetra butyl ammonium hydroxide solution and acetonitrile. Ultra violet detection was carried out at $210 \mathrm{~nm}$. The method was modified with respect to linearity, precision, accuracy, selectivity, specificity and ruggedness. The results obtained revealed that lisinopril dihydrate was an active product slightly changed under stress conditions.
\end{abstract}

\section{Keywords}

Lisinopril Dihydrate, Stability, UV Light, Sun Light, High Temperature, Pharmaceutical Excipients, High Performance Liquid Chromatography

\section{Introduction}

Lisinopril is chemically described as l-proline, 1-[N2-(1-carboxy-3-phenylpropyl)-l-lysyl]-, dihydrate or (2s)-1(2s)-6-Amino-2-[[(1s)-1-carboxy-3-phenylpropyl] amino] hexanoyl] pyrrodine-2-carboxylic acid dihydrate. Its empirical formula is $\mathbf{C}_{21} \mathbf{H}_{31} \mathbf{N}_{3} \mathbf{O}_{5} \cdot \mathbf{2} \mathbf{H}_{2} \mathbf{O}$. It is a white or almost white, crystalline powder with a molecular weight of 441.52. It's soluble in water, sparingly soluble in methanol; practically insoluble in acetone and in anhydrous ethanol [1] [2].

Lisinopril is used to treat high blood pressure (hypertension), congestive heart failure, and to improve survival after a heart attack. Lisinopril works by causing blood vessels to relax, lowering blood pressure and increasing the supply of blood and oxygen to the heart. For this reason it is also sometimes used, alongside other medicines, 
to treat circulatory problems associated with diabetes [3]-[5].

Drug stability plays a very important role in pharmaceutical research and development for a newly developed drug product, stability analysis not only provides useful information regarding the degradation of the drug product, but also determines an expiration dating period of the drug product.

For the purpose of safety and quality assurance, most regulatory agencies such as FDA require that an expiration dating period be indicated on the immediate container label for every drug product on the market [6].

Stability testing is the primary tool used to assess expiration dating and storage conditions for pharmaceutical products. Many protocols have been used for stability testing, but most in the industry are now standardized on the recommendations of the International Conference on Harmonization [7]-[9]. These guidelines were developed as a cooperative effort between regulatory agencies and industry officials from Europe, Japan, and the United States.

Degradation reactions in pharmaceutical formulations take place at definite rates and are chemical in nature. They depend on such conditions as concentration of reactants, temperature, $\mathrm{pH}$, radiation, and catalysts.

The common stress conditions include acidic $\mathrm{pH}$, basic $\mathrm{pH}$, neutral $\mathrm{pH}$, different temperature and humidity conditions, oxidation, reduction and photo-degradation [8]. These studies help to determine the significantly related substances to be used in method development, and to determine the degraded product formed under stress conditions [10].

The present study aimed at investigation of the photo-thermal stability of lisinopril dihydrate.

\section{Materials and Methods}

\subsection{Chemicals and Reagents}

All chemicals and reagents used were of a HPLC grade. Lisinopril dihydrate was kindly supplied from Zhejiang Huahai Pharmaceutical CO. Ltd. (Taizhou, China). Tetra-n-butyl ammonium hydroxide $40 \%$ aqueous solution was obtained from AppliChem, Germany. Acetonitrile HPLC grade was obtained from BDH Labs, England. Orthophospharic acid 85\% were obtained from BDH laboratory, England.

\subsection{Equipment}

1) HPLC was performed using a Waters Breeze 2 HPLC System consisting of LC 1525 binary pump, 2489 UV/Visible Detector, and 2707 auto sampler.

2) Column used was C18, Waters Spherisorb ${ }^{\circledR} 5.0 \mu \mathrm{m}$ ODS2 $4.6 \mathrm{~mm} \times 250 \mathrm{~mm}$.

3) Sartorius model cp224s balance.

4) Mi 180 Bench pH meter, MARTINI instruments.

5) Ultra violet radiation (UV Lamp $\lambda 254$ - $\lambda 265$ ) with Obligatory eye protection-Model-M014492 BDH-England.

\subsection{Preparation of Mobile Phase}

Mix a solution of $0.03 \mathrm{M}$ Tetra butyl ammonium hydroxide (Solution was prepared by diluted $20 \mathrm{ml}$ of tetra butyl ammonium hydroxide $40 \%$ aqueous solution to $800 \mathrm{ml}$ with distilled water and adjusted to $\mathrm{pH} 6.5$ with $10 \%$ of aqueous orthophosphoric acid and diluted up to $1000 \mathrm{ml}$ with distilled water) and acetonitrile with a ratio of 3:1 respectively and degassed.

\subsection{Preparation of Standard Stock Solutions}

Stock standard solution having concentration of $0.1 \mathrm{mg} / \mathrm{ml}$ was prepared by dissolving pure drug of lisinopril dihydrate in distilled water.

\subsection{Preparation of Solution for Calibration Curve}

Standard stock solution was $0.1 \mathrm{mg} / \mathrm{ml}$; these solutions were further diluted to get solutions of concentrations 10 , 20, 30, 40, and $50 \mu \mathrm{g} / \mathrm{ml}$ of lisinopril dihydrate. 


\subsection{Preparation of Lisinopril Dihydrate Sun Decomposed Product}

Few grams of lisinopril dihydrate solid were placed between two glass plates $(20 \times 20 \mathrm{~cm})$, sealed with gum tape and directly exposed to sunlight for six months (March to August). Samples were taken every month and tested for degradation by HPLC.

$30 \mathrm{mg}$ of lisinopril dihydrate sun decomposed was dissolved in $100 \mathrm{ml}$ water and analyzed by RP-HPLC.

$30 \mathrm{mg}$ of lisinopril dihydrate was weight and dissolved in $100 \mathrm{ml}$ water. The solutions were exposed directly to sun light. Five ml of samples were taken at 30, 60, 90, 120, 150 - 300 minutes, transferred to 25 ml volumetric flask and the volume was completed to the mark with the distilled water and analyzed by RP-HPLC

\subsection{Preparation of Lisinopril Dihydrate UV Decomposed Product}

$30 \mu \mathrm{g} / \mathrm{ml}$ of lisinopril dihydrate solution was prepared and transferred to a stoppered tube. The solutions were placed under UV radiation at $\lambda 254 \mathrm{~nm}$. Five $\mathrm{ml}$ of samples were taken at 30, 60, 90, 120, 150 - 300 minutes, transferred to $25 \mathrm{ml}$ volumetric flask and the volume was completed to the mark with the distilled water.

\subsection{Preparation of Lisinopril Dihydrate Buffering Thermal Decomposed Product}

Serial buffer solutions with $\mathrm{pH}$ 2, 4, 6, 8, 10, and 12 were prepared. $25 \mathrm{ml}$ of lisinopril dihydrate aliquots (30 $\mathrm{mg} / 100 \mathrm{ml}$ water) were pipette, and separately transferred to six $100-\mathrm{ml}$ volumetric flask and each volume was completed to $100-\mathrm{ml}$ with one of the universal buffer solution mentioned above. Each sample was put in water path thermo stated at $70^{\circ} \mathrm{C}$. Ten mls of each sample were taken at $0,30,60,90,120,300$ minutes and transferred separately to a small beaker and cooled with iced water; $5 \mathrm{ml}$ from these solutions were transferred to 25 $\mathrm{ml}$ volumetric flasks, and the volume was completed to the mark with distilled water (Table 1) and analyzed by RP-HPLC.

\subsection{Preparation of Lisinopril Dihydrate with Pharmaceutical Excipients Sun, UV, and Thermal Decomposed Product}

The required pharmaceutical excipient was weighted (Table 2), transferred to a $100 \mathrm{ml}$ volumetric flask and dissolved with small volume of distilled water. Twenty-five $\mathrm{ml}$ of lisinopril dihydrate ( $30 \mathrm{mg} / 100 \mathrm{ml}$-water) was added to the flask containing the pharmaceutical excipients; the volume was completed to the mark with distilled water. The flask was exposed directly to sunrays. Samples of 10-mls were taken at 15, 30, 45, 60, 75, 90, and 105 and 120 minutes, each sample was separately transferred into $25 \mathrm{ml}$ volumetric flask and diluted to the volume with distilled water (Table 2) and analyzed by RP-HPLC. The some preparations were repeated under UV light, sun light and in a thermostated water path at $70^{\circ} \mathrm{C}$.

\section{Results and Discussion}

HPLC method was modified for the analysis of lisinopril dihydrate using the mobile phase mentioned above with a flow rate $1.0 \mathrm{ml} / \mathrm{min}$, wave length detection at $210 \mathrm{~nm}$ on a C18 column (waters $250 \times 4.6 \mathrm{~mm}, 5 \mu \mathrm{m}$ ) (Table 3), revealed good resolution and peak shape for lisinopril dihydrate (Figure 1).

Modified HPLC method was found satisfactory for analysis of lisinopril dihydrate and degraded products. System suitability parameters were used to the analysis lisinopril dihydrate sun, UV, and thermal decomposed.

For quantitative determination of lisinopril dihydrate, the calibration curve was plotted for the concentration range $10-50 \mu \mathrm{g} / \mathrm{ml}$. Calibration curve plots were constructed using five standard solutions of different concentration .The statistical parameters and linear regression equation calculated from the calibration curve is given in Table 4. The linear regression $\left(r^{2}\right)$ was 0.9994 (Figure 1 and Figure 2). Limit of Detection (LOD) was calculated by using formula $3.3(\sigma / \mathrm{S})$ where $\sigma$ is standard deviation of the response and $\mathrm{S}$ is slope of the calibration curve [11]-[13]. LOD was found to be $0.61 \mu \mathrm{g} / \mathrm{ml}$. Limit of Quantitation (LOQ) was calculated by using formula $10(\sigma / \mathrm{S})[11]$-[13] was found to be $1.87 \mu \mathrm{g} / \mathrm{ml}$.

With the above selected method parameters, system suitability testing provided adequate good resolution for analysis to be performed for the resolution of lisinopril dihydrate and its degradation products. The stability of the lisinopril dihydrate solid was tested exposed directly to sun light for six months, sample was tested every month by HPLC (Table 5). It's was found that, lisinopril dihydrate solid were slightly affected by sunlight in a way dependent upon time of expose to sunlight, 
Table 1. The effect of $\mathrm{pH}$-value on the reaction rate of lisinopril dihydrate thermal-decomposed.

\begin{tabular}{cc}
\hline $\mathrm{pH}-$ value & Reaction rate $(\mathrm{k})-\mathrm{min}^{-1}$ \\
\hline 2 & 0.0047 \\
4 & 0.0049 \\
6 & 0.0053 \\
8 & 0.0054 \\
10 & 0.0058 \\
12 & 0.0066 \\
\hline
\end{tabular}

Table 2. The effect of some pharmaceutical excipients on the stability of lisinopril dihydrate sun decomposed.

\begin{tabular}{|c|c|c|c|c|c|}
\hline \multirow{2}{*}{ Excipient name } & \multirow{2}{*}{$\begin{array}{l}\text { Concentration } \\
\% w / w\end{array}$} & \multirow{2}{*}{$\mathrm{pH}$} & \multicolumn{3}{|c|}{ Reaction rate $\mathrm{k}-\mathrm{min}^{-1}$} \\
\hline & & & Sun & UV & Temp \\
\hline Dibasic Ca-ph & 0.01 & 7.60 & 0.00007 & 0.00026 & 0.00038 \\
\hline Maize starch & 0.01 & 5.45 & 0.00002 & 0.00063 & 0.00015 \\
\hline Mg. Stearate & 0.01 & 7.44 & 0.00005 & 0.00030 & 0.00058 \\
\hline Talcum & 0.01 & 6.26 & 0.00003 & 0.00003 & 0.00063 \\
\hline Avicel (MCC) & 0.01 & 6.73 & 0.00007 & 0.00102 & 0.00055 \\
\hline $\begin{array}{c}\text { Control (Lisino. } 2 \mathrm{H}_{2} \mathrm{O} \\
\text { without excipients) }\end{array}$ & - & & 0.00018 & 0.00063 & 0.00063 \\
\hline
\end{tabular}

Table 3. Conditions used for chromatography analysis.

\begin{tabular}{ccc}
\hline Sr.NO & Parameter & Condition used for analysis \\
1 & Mobile phase & $\begin{array}{r}\text { Tetra butyl Ammonium hydroxide solution } \\
(0.1 \mathrm{~N} \text { aqueous }) \mathrm{pH} \text { 6.5 with orthophospharic } \\
\text { acid }(10 \% \text { aqueous }): \text { Acetonitrile }(3: 1)\end{array}$ \\
2 & Flow rate & $1.0 \mathrm{ml} / \mathrm{min}$ \\
3 & Detection Wavelength & $210 \mathrm{~nm}$ \\
4 & Sample injector & $50 \mu \mathrm{l}$ loop \\
5 & Column & C18 waters $(4.6 \times 250 \mathrm{~mm}, 5 \mu \mathrm{m})$ \\
\hline
\end{tabular}

Table 4. Results of standard calibration curve for the analysis of Lisinopril dihydrate by HPLC $\left(r^{2}=0.9994\right)$.

\begin{tabular}{cc}
\hline Concentration of lisinopril dihydrate $\mu \mathrm{g} / \mathrm{ml}$ & peak height \\
\hline 10 & 89766.31 \\
20 & 132167.84 \\
40 & 175652.70 \\
50 & 219521.63 \\
\hline
\end{tabular}

$\mathrm{LOD}=0.61 \mu \mathrm{g} / \mathrm{ml}, \mathrm{LOQ}=1.87 \mu \mathrm{g} / \mathrm{ml}$. 
Table 5. The effect of time on the reaction rate of lisinopril dihydrate solid sun-decomposed.

\begin{tabular}{cc}
\hline Interval time/month & Reaction rate (k)-month ${ }^{-1}$ \\
\hline 1 & 0.0005 \\
2 & 0.0187 \\
3 & 0.0342 \\
4 & 0.0475 \\
5 & 0.0599 \\
6 & 0.0774 \\
\hline
\end{tabular}

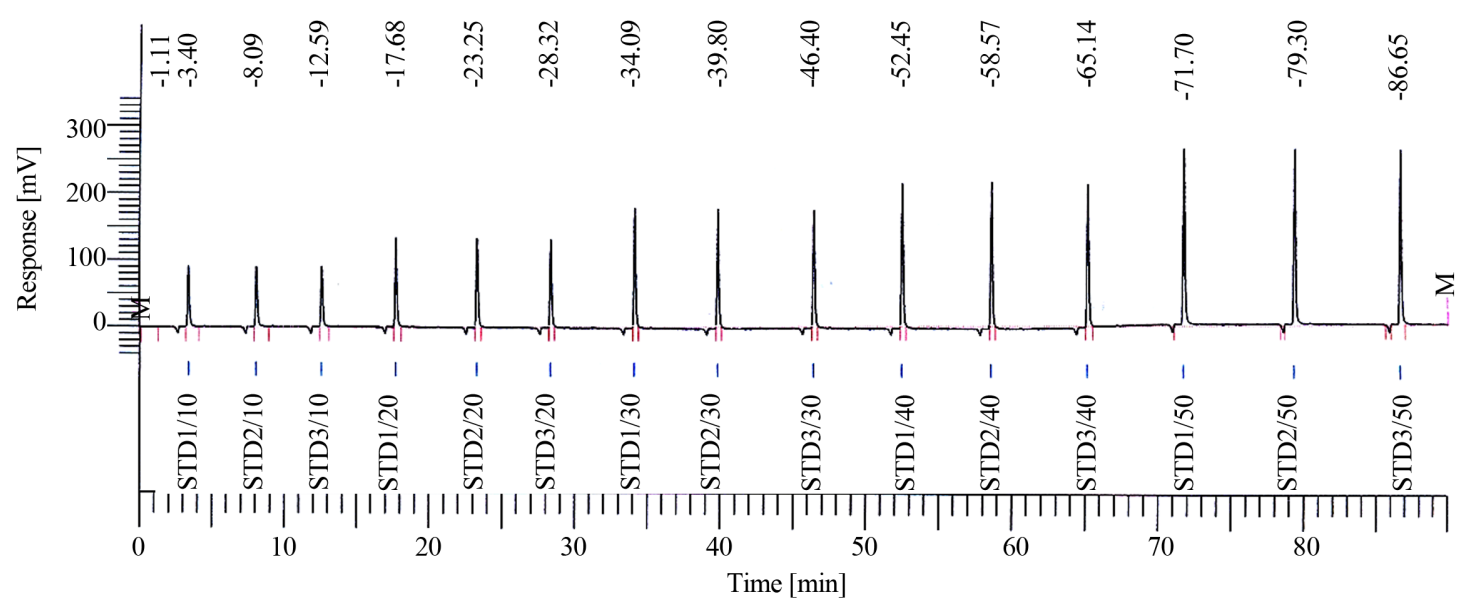

Figure 1. Test HPLC chromatogram for the analysis of different concentrations of lisinopril dihydrate reference to illustrate calibration curve of method.

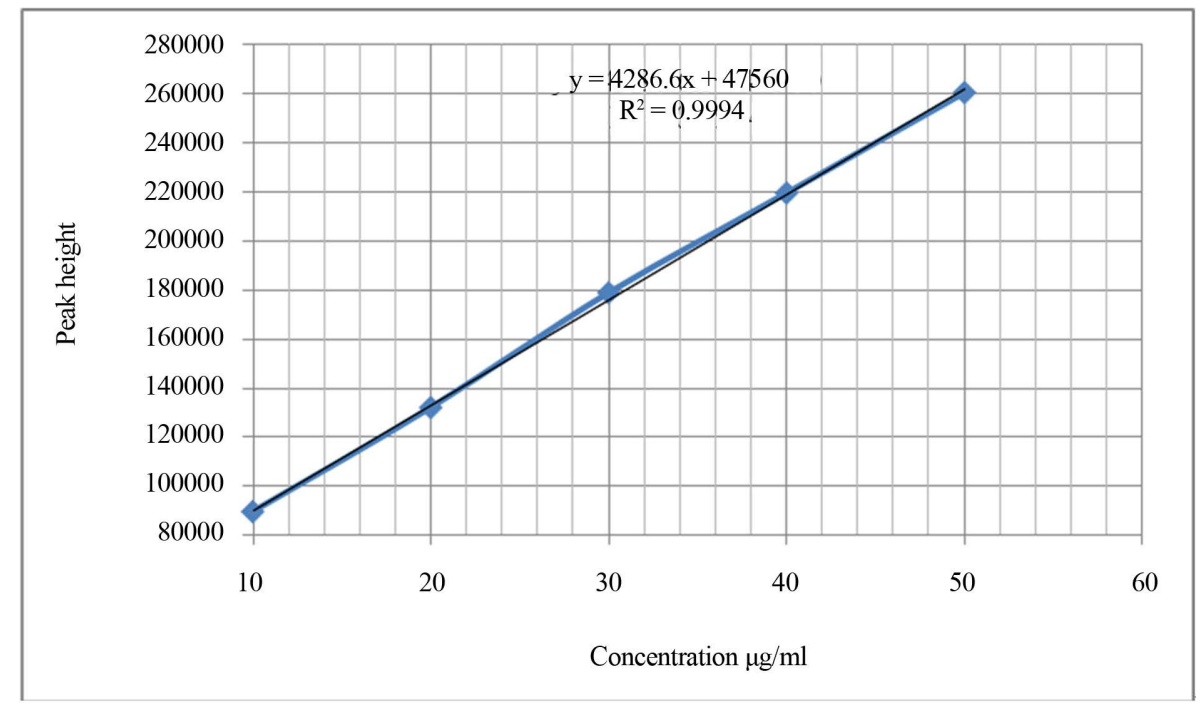

Figure 2. Amount injected versus peak height of Lisinopril dihydrate standard to demonstrate calibration curve (linearity). 
Lisinopril dihydrate sun-decomposed reveals that it lost about $10 \%$ of its initial concentration when directly exposed to sun light over period of six month (March to August). The reaction rate of lisinopril- $2 \mathrm{H}_{2} \mathrm{O}$ sun-decomposed was found to be increase with the increase of time of exposure to sun light. It was clear that lisinopril- $2 \mathrm{H}_{2} \mathrm{O}$ in aqueous media was rapidly degraded when compared with that in solid forms Table 6. It is a straight forward observation, as it is a well known fact that chemistry in the aqueous state is more rapid reaction than that in the solid form [14]. The stability of the lisinopril dihydrate solution UV decomposed was tested by placed sample under UV light at $254 \mathrm{~nm}$ for interval times. The UV sample was analysis using RP-HPLC. The results of analyzed UV decomposed products were presented are shown in Table 7. The effect of UV light on the stability of lisinopril- $2 \mathrm{H}_{2} \mathrm{O}$ solution was studied. The drug was found to be less stable than affected of sun light (Table 6).

The reaction rate of thermal decomposition was increased with the increase in temperature (Table 8). Lisinopril dihydrate was thermally unstable with increase $\mathrm{pH}$ value (Table 1 ). In this work, the effect of some pharmaceutical excipients on the stability of lisinopril- $2 \mathrm{H}_{2} \mathrm{O}$ Sun, UV, and thermal decomposed were studied, some excipients were found to decrease the reaction rate as talcum, dibasic calcium phosphate (dibasic Ca.ph), and magnesium stearate (Mg.S), and other were increase the reaction rate such as a vicel and Maize starch (Table 2) by sun, UV, and thermal effected respectively.

Table 6. The effect of time on the stability of lisinopril dihydrate solution sun-decomposed.

\begin{tabular}{cc}
\hline Inter val time/min & Reaction rate K- $\mathrm{min}^{-1}$ \\
\hline 30 & 0.00007 \\
60 & 0.00030 \\
90 & 0.00058 \\
120 & 0.00080 \\
150 & 0.00100 \\
\hline
\end{tabular}

Table 7. The effect of time on the stability of lisinopril dihydrate solution UV Light decomposed.

\begin{tabular}{cc}
\hline Interval time/min & Reaction rate K-min ${ }^{-1}$ \\
\hline $30 \mathrm{~min}$ & 0.0006 \\
$60 \mathrm{~min}$ & 0.0015 \\
$90 \mathrm{~min}$ & 0.0029 \\
$120 \mathrm{~min}$ & 0.0051 \\
$150 \mathrm{~min}$ & 0.0076 \\
\hline
\end{tabular}

Table 8. The effect of temperature on the reaction rate of lisinopril dihydrate solution.

\begin{tabular}{cc}
\hline Temperature $\left({ }^{\circ} \mathrm{C}\right)$ & Reaction Rate $(\mathrm{K})-\mathrm{min}^{-1}$ \\
\hline $40^{\circ} \mathrm{C}$ & 0.00011 \\
$50^{\circ} \mathrm{C}$ & 0.00015 \\
$60^{\circ} \mathrm{C}$ & 0.00022 \\
$70^{\circ} \mathrm{C}$ & 0.00063 \\
$80^{\circ} \mathrm{C}$ & 0.00076 \\
$90^{\circ} \mathrm{C}$ & 0.00081 \\
$100^{\circ} \mathrm{C}$ & 0.0010 \\
\hline
\end{tabular}




\section{Conclusions}

It can be concluded from this work that lisinopril dihydrate is found to be stable under sun light and UV light into solid and liquid forms. The HPLC method was found to be suitable for the study of kinetic of photo-thermal decomposition of lisinopril and its quantitative determination in the presence of photo-thermal decomposition products.

Some pharmaceutical excipients were found to enhance the stability of cefixime trihydrate; therefore it's recommended that such excipients be used in the formulation.

\section{References}

[1] British Pharmacopeia (2010) Volume II. Lisinopril Dihydrate. 1279-1280.

[2] United States Pharmacopeia 34-NF 29 (2011) Volume (3). Lisinopril dihydrate. USP-National Formulary Convention, Rockville, Maryland, 3320.

[3] Lancaster, S.G. and Todd, P.A. (1988) Lisinopril. A Preliminary Review of Its Pharmacodynamic and Pharmacokinetic Properties, and Therapeutic Use in Hypertension and Congestive Heart Failure. Drugs, 35, 646-669. http://dx.doi.org/10.2165/00003495-198835060-00003

[4] Sean, C.S. (2009) Lisinopril Dihydrate. 36th Edition, Royal Pharmaceutical Society of Great Britain (RPS) Publishing, Martindale, 1325-1326.

[5] Simpson, K. and Jarvis, B. (2000) Lisinopril: A Review of Its Use in Congestive Heart Failure. Drugs, 59, $1149-1167$. http://dx.doi.org/10.2165/00003495-200059050-00012

[6] Food and Drug Administration (FDA) (2000) Analytical Procedures and Methods Validation: Chemistry, Manufacturing and Controls Documentation; Availability. Federal Register (Notices), 65, 52776-52777.

[7] Food and Drug Administration (FDA) (1987) Guideline for Stability Studies for Human Biologics. Office of Drug Standards, New York, 3-10.

[8] International Conference on Harmonization (ICH) (2003) Stability Testing New Drug Substance and Drug Products, Q1A [R2].

[9] International Conference on Harmonization (ICH) (1996) Stability Testing: Photostability Testing of New Drug Substance and Drug Products, Q1B.

[10] International Conference on Harmonization (ICH) (2003) Evaluation for Stability Data, Q1E.

[11] Beckett, A.H. and Stenlake, J.B. (1988) Chromatography. Chapter Four. Practical Pharmaceutical Chemistry. Part One. Athlone Press, London, 115-128, 157-174.

[12] Snyder, L.R. and Kirkland, J.J. (1997) Practical HPLC Method Development. Wiley Interscince, Chichester, London, 15-35.

[13] Meyer, V.R. (1994) Practical High Performance Liquid Chromatography. J. Wiley and Sons, Chichester, London, 1025.

[14] Amin, M.I. and Bryan, J.T. (1973) Kinetic Factors Affecting Stability in Aqueous Formulation. Pharmacy Science, 62, 1768-1771. 